\title{
HARNESSING POTENTIAL OF ICT TO BENEFIT RURAL INDIA
}

\author{
by
}

\author{
1 Dr. Bajrang Singh Rathore
}

${ }^{2}$ Mrs. Garima Singh

"The Government would implement a comprehensive programme to accelerate e-governance at all levels of the Government to improve efficiency, transparency and accountability at the Government-Citizen Interface."

Hon'ble Prime Minister, 15th August 2002.

'If a society cannot help the many who are poor, it cannot save the few who are rich.' So how would India go about saving the 70 per cent of its population that resides in rural areas with no adequate electricity, water supply, or even a sustainable means of income generation - forget exposure to technology? The first step here, perhaps, should be to arm this marginalised majority with information and education, not through the traditional means of teacher-school building mode but via e-Learning. And this is not an impossible dream we are scaling. It is very much an achievable target and India is showing all symptoms of success. It is heartening to see that the Indian e-Learning industry is estimated to grow very rapidly in the coming years.

The Indian government has also taken significant steps towards dissemination of information through a number of e-Learning projects, not only for rural students but for the community at large. These projects can be divided into three heads - social development projects to provide informal IT training to the rural illiterate mass, community information services project for people who have minimum knowledge and finally school based curriculum projects imparting computer education to rural students.

\section{Internet Penetration in India}

However, there is still a lot more to be done. Improvement of connectivity is a primary area of concern. With a PC density of 4.94 per 1,000 people and a tele-density of 32 fixed lines per 1,000 people, India needs to increase penetration in terms of PCs and communication lines for any e-Learning project to be successful. The high cost of ownership, which proves a barrier towards proliferation of access devices, needs to be lowered. Due to high tariff levels, the cost of hardware in India is significantly higher as compared to the rest of the world. For instance, a $\mathrm{PC}$ in India costs around 24 months of average percapita income as compared to China's 4 months and USA's 12 days.

The Telecom Regulatory Authority of India (TRAI), which has started preparing a new policy for increasing the penetration of Internet and broadband, however has admitted that much needed to be done and this is because the situation was far from satisfactory in terms of capacity, subscriber base and growth rate of Internet and broadband usage. Current Internet subscriber base is only 0.4 per cent of the population and the growth rate of internet subscribers has become low; the usage of broadband services is on an even smaller scale-a mere 0.02 per cent. The number of internet connection per 100 persons is 58,11 and 2 for Korea, Malaysia and China, as compared to India's 0.4 per cent. On the other hand, the world over, Internet has evolved into a platform for free speech that is being accessed by nearly 850 million users.

1 Lecturer in Public Administration, Govt Dungar College, Bikaner

2 PhD Scholar, Maharaja Ganga Singh University, Bikaner 
The state-owned Videsh Sanchar Nigam Limited (VSNL) launched Internet Services in India in August 1995. For the first four years, VSNL was the sole provider of Internet Services in the Country. In November 1998, the Government ended VSNL's monopoly and allowed provisioning of Internet Services by Private Operators. The Terms and Conditions of the ISP's License were unusually liberal with no License Fee and allowed unlimited number of players. ISPs could set their own tariffs and even their own International Gateways. This led to the free-wheeling growth of internet users in India.

\begin{tabular}{|l|l|l|l|l|}
\hline YEAR & Users & Population & $\%$ Penetration & Usage Source \\
\hline 1998 & $1,400,000$ & $1,094,870,677$ & $0.1 \%$ & TU \\
\hline 1999 & $2,800,000$ & $1,094,870,677$ & $0.3 \%$ & TU \\
\hline 2000 & $5,500,000$ & $1,094,870,677$ & $0.5 \%$ & TU \\
\hline 2001 & $7,000,000$ & $1,094,870,677$ & $0.7 \%$ & TU \\
\hline 2002 & $16,500,000$ & $1,094,870,677$ & $1.6 \%$ & TU \\
\hline 2003 & $22,500,000$ & $1,094,870,677$ & $2.1 \%$ & TU \\
\hline 2004 & $39,200,000$ & $1,094,870,677$ & $3.6 \%$ & C.I. Almanac \\
\hline 2005 & $50,600,000$ & $1,112,225,812$ & $4.5 \%$ & C.I. Almanac \\
\hline 2006 & $40,000,000$ & $1,112,225,812$ & $3.6 \%$ & IAMAI \\
\hline 2007 & $42,000,000$ & $1,129,667,528$ & $3.7 \%$ & IWS \\
\hline 2009 & $81,000,000$ & $1,156,897,766$ & $7.0 \%$ & IU \\
\hline 2010 & $100,000,000$ & $1,173,108,018$ & $8.5 \%$ & IWS \\
\hline
\end{tabular}

Pakistan, a poorer country than India where terrorism has taken a heavy toll has internet penetrations of more than 11 percent as compared to India's 4.5 percent - more than double as compared to India. Even countries like Sri Lanka (5.8), Philippines (6.2), Indonesia (7.9) rank much higher than India. If countries like Hong Kong and Singapore, India's chart-line would not even be visible as these countries have over 70 to 80 percent of people using Internet!

\section{Vignettes of few initiatives taken leading to proliferation of ICT in Rural India}

The last couple of years have seen e-governance drop roots in India. IT enables the delivery of government services as it caters to a large base of people across different segments and geographical locations.

- Social development projects like Akshaya, Aqua Choupal, Gramin Gyan Kendra (village knowledge centre), have been initiated which focus on generating network of information centres, employment \& investment opportunities in rural areas.
- Community information services like e-Choupal and Planters Net have been designed to disseminate information on rural farm-gate price realisation, cut transaction costs, supply of high quality farm inputs etc.

- School based projects like School Net India, Uttaranchal's Aarohi and Mapping the Neighbourhood support education infrastructure for enhancing the quality of human capita and community mapping and local content development involving school children, respectively. 
- Wipro and Intel have jointly launched a low-cost solution and technology project to meet the needs of education segment for the underprivileged in India, called 'i-shiksha'.

- Microsoft Corporation India Pvt Ltd announced its plans to spend \$20 million on its 'Project Shiksha', which will be rolled out in ten states across the country in a phased manner.

- In its drive to familiarize rural areas with IT, two of India's reputed IT firms recently rolled out a campaign in Jaipur to familiarize and enthuse rural people about the benefits of information and communications technology (ICT) for socio-economic empowerment

- Google is also betting heavily on the mobile platform (as PC penetration is low) and plans to introduce services like Google Talk (instant chat application), and Google Maps through tie-ups with Indian mobile operators.

- BPO operations are heading into rural India. There is a big cost advantage to a company locating in rural areas because the infrastructure costs are low. It is believed there are 80 to 90 million people that could be trained to take care of the back-office needs of the entire world.

- IT-rural.com guides farmers on sowing suitable varieties of seeds of crops in demand, current trends and prevailing prices in the neighbourhood. Forward and backward linkages with financial institutions and buyers are also enabled.

- Rural India is going Wi-Fi. At present, hybrid Wi-Fi and WiMAX deployments are bringing broadband connectivity to previously unconnected rural and urban areas. Moreover, dual-mode Wi$\mathrm{Fi} /$ cellular handsets are eyed to bring higherthroughput Internet connectivity to the country's citizens who do not own computers.

- Indian Villagers Pedal Wireless. It is planned that in end of the year, 5,000 young men on bicycles carrying mobile phones equipped with CDMA Wireless Local Loop will ride into 5,000 West Bengal villages. Not only will the endeavor provide these men with a steady source of income - they keep 25 percent of profits from all calls made - but they will also bring telephone services to village doorsteps for the first time.
- The simputer, a handheld device designed for rural villagers is slowly gaining popularity.

- Private sector initiatives such as ITC's e-Choupal, HUL's Project Shakti, Microsoft's Project Shiksha and Google's Internet bus among various others, helped to create awareness and usage.

- Pathinettangudi is a village where IT is a way of life. This village some $35 \mathrm{~km}$ from Madurai, presents the look of just another underprivileged village. However, a silent IT revolution is brewing in the tiny hamlet where the illiterate farm workers use web cams, voice mail and e-mail regularly.

\section{Rural India and Internet}

The above projects might make fascinating read, but the rural reality speaks a different language. There is a considerable disparity between rural and urban literacy percentage. Compared to an almost 80 per cent literacy rate in urban India, that in rural areas is only 56 per cent. Added to this, India has 192 million illiterate women, which is nearly one-third of all illiterate women in the world. Bringing them into the fold of e-Learning will be a humungous task. Further, the average teacher:student ratio at primary level is 1:58 in rural regions. The current e-Learning initiatives are yet to narrow this gap.

$\mathbf{8 4 \%}$ of rural India is unaware of Internet. Although, Urban India has adopted Internet in large numbers (especially younger generation), Internet penetration in Rural India is close to zilch. Even though Government is making huge efforts to increase the penetration, it seems to be failing miserably.

According to a survey conducted jointly by IAMAI and IMRB in 2010, about 84 percent of people in rural India are not aware of Internet. The organizations believe that this lack of awareness is the primary reason that has prevented internet take-up in rural India. The research further found that 38 percent of rural inhabitants feel no need for internet access. Further reasons for not using the internet include lack of an internet access point (31\%), unfamiliar with computers $(31 \%)$, no computer available $(28 \%)$, need for guidance $(28 \%)$, no electricity $(22 \%)$, and not being able to afford internet (10\%). 
At present, common service centers and cyber cafés serve as the primary mode of accessing internet, with more than 70 percent of the rural population accessing the internet this way

However, things are changing fast and in the right direction. It is heartening to note that a large portion of the growth of Internet is taking place in rural areas. Small towns contributed to only $5 \%$ of internet usage in year 2000, which over a period of 9 years has grown to healthy $36 \%$ and for the first time Small towns growth has overtaken the Internet usage in Urban areas.

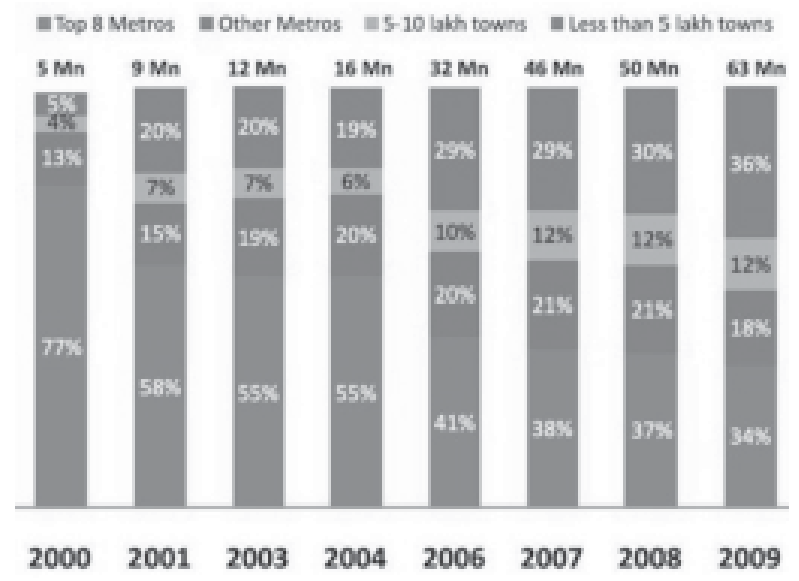

The Internet and Mobile Association of India (IAMAI) and IMRB International have provided an insightful research about the internet in rural India. The telecom penetration in urban India is reaching a saturation state, realising which they are trying to break into the rural market. The report showed that the total number of active internet users in rural area is projected to rise by a whopping $98 \%$, from 12.1 million in December 2010 to 24 million by December 2011.

An improved internet awareness in rural areas was credited to the fast growth experienced. Government initiative was also conducted to facilitate internet networks and 'common service centers' (or cyber cafes) both of which increased in 2010. Back in October 2010, the Government had planned that India's rural area would be going through a network facelift at a cost of US\$3.4 billion. While it has only been 6 months, the initiative has been pretty successful, at least in statistical terms. Most of the internet users in rural areas have had to access internet from Common Service Centers (CSC).

\section{National e-Governance Plan (NeGP),}

Government initiatives facilitated by DIT (Department of Information Technology) such as National e-Governance Plan (NeGP), State Wide Area Network (SWAN) and CSC are increasingly maturing. As per latest reports provided by the DIT, there are about 90,000 CSCs operational in various parts of India. With India having about 600,000 villages, each CSC on an average serves about six villages approximately.

The World Bank on March 31, 2011 has approved $\$ 150$ million to India to accelerate the implementation of its National e-Governance Plan (NeGP), a flagship e-governance initiative of the Government of India aimed at transforming the service delivery system across the country. The Approved loan, from the International Bank for Reconstruction and Development (IBRD), has a 5-year grace period, and a maturity of 18 years.

The e-Delivery of Public Services Development Policy Loan, approved will support NeGP's countrywide plans of increasing online services for citizens in their locality. Projects which have been identified for such online computerized services on a priority basis also known as e-services - include birth and death registration, tax filing, land records, driver's licenses and vehicle registration, passports and visas, agricultural extension services, and a wide range of municipal and panchayat (local government) level services.

It will also enable e-services for a number of critical private sector services such as banking, insurance, and trade. While this World Bank loan will not target specific services per se, it will initiate policy and institutional actions that will affect all services.

The loan will support NeGP - approved in May 2006 as a national program - to operate on a single common IT infrastructure, thus allowing faster and easier sharing of information between departments, saving infrastructure costs, and lowering cost of service delivery for citizens as well as government agencies. Citizens will no longer have to go to multiple 
departments, but will have the option of accessing e-services either through the internet on the government's common website, or through a 'single window' Common Service Centers (CSC), set up to assist villages or remote areas.

Though NeGP has made substantial progress since its adoption, implementation lags behind the Gol's expectations.

A majority of citizens in rural areas still do not have access to e-services. Plans are being drawn to extend such facilities in some 250,000 panchayats where rural users can access public services online. In the medium term, some of the major impediments identified are weak capacities of states to prepare and implement projects; partial development of technical standards; need for an effective monitoring system; insufficient participation from citizens and end-users; inadequate identification of real beneficiaries in e-transactions; limited internet penetration in rural/remote areas; inadequate use of mobile platform as a service delivery channel and need for re-orientation of government processes and officials to implement it.

\section{Steps to address challenges to ICT in Rural India}

The following steps could help in arresting the above problems:

- Connectivity options to the rural areas can be improved by using wireless access. For instance, corDECT is an advanced, wireless access system developed by the TeNeT group of IIT Madras, Midas Communications and Analog Devices. In addition, cybercafes and village information kiosks will enhance the reach of IT.

- Need to reduce the tariff levels.

- Inventions such as the Simputer can reduce costs by providing affordable computing. At $\$ 200$ a piece, the Simputer offers computing facilities at a drastically lower cost compared to $\$ 650$ for a PC. Further, it has a local language interface. Development of Advanced Computing (C-DAC) design an "India PC" at a price of Rs. 9,000 is a welcome step.
- Use of open source software will not only be cost effective but can also meet the localisation demands of the huge linguistic diversity of India. Further, open source software can also be used on old hardware.

- Third world countries are bypassing the costly process of stringing copper wires by leaping to wireless connectivity. The groundbreaking Indian Institutes of Technologies are applying the latest telecoms tools to the poorest communities. At the Indian Institute of Technology Madras, innovative technologies are being developed for a commercial spin-off to bring telephony and Internet connectivity to rural India.

- The Internet is becoming a less alien phenomenon in the countryside, but the development of locallanguage applications holds the key to connecting more of the 568 million who live in rural India to the World Wide Web, a survey has found.

- There is a need for localizing online content to spread Internet usage in rural India. The rural market holds tremendous potential for any media. However, for Internet to flourish in rural India, the applications need to be in vernacular languages, preferably with text to speech capabilities.

- Last mile connectivity in India continues to remain a major challenge as the delivery of e-services is dependent on the quality of broadband access in remote areas. However, the mobile tele-density now stands at over 60 percent and is expected to increase. In the near future, this is likely to facilitate delivery of mobile-based government services at a low cost to citizens.

\section{Conclusion}

Dr. A.P.J. Abdul Kalam, has also suggested that a comprehensive E-governance framework should be evolved in the country, which would entail setting up an E-governance commission or an empowered board-with a view to ensure transparency in citizengovernment interface. It would also entail setting up a multipurpose secure, authentic national citizen ID database as the primary data for all E-governance services and online issue of citizen ID cards seamlessly. 
Dr. Kalam also stressed the need for languageindependent operating systems, databases and application servers and mail servers in Indian languages. He added that since India has proven core competence in IT and communications, the possibility of success to bringing in transparency in administration through E-governance is possible. Finally, to quote, "This is my dream. Is it possible? If possible when shall we have it? Can we provide governance to our one billion people

Its influence and impact on communications, commerce and intellectual freedom is unprecedented. Governments are therefore advised to set for themselves a deadline to create the basic infrastructure for wider access of the internet and adopt policies that would bridge the digital divide. It is believed that despite a national focus on E-governance and information and communication technology for development, few initiatives have become truly interactive. In order to widen the user base, a basket of measures such as attractive reductions in telephone charges for dial-up access, the commissioning of a national internet exchange and incentives for Internet service providers to offer diverse access choices is urgently called for. 